\title{
Analysis on the Influence of Policy Factors in Innovating Behavior for Chinese Orphan Drugs' Industry
}

\author{
Baxian $\mathrm{Yi}^{1,2}$, Guangping Wang ${ }^{3}$, Yanfei $\mathrm{Huo}^{2} \&$ Xiaoming $\mathrm{Wu}^{1}$ \\ ${ }^{1}$ China Pharmaceutical University, Nanjing, China \\ ${ }^{2}$ China State Institute of Pharmaceutical Industry, Shanghai, China \\ ${ }^{3}$ Shanghai Institute for Food and Drug Safety, Shanghai, China \\ Correspondence: Xiaoming Wu, China Pharmaceutical University, Nanjing 210009, China. E-mail: \\ xmwu@cpu.edu.cn
}

Received: September 12, 2014 Accepted: October 10, 2014 Online Published: October 29, 2014

doi:10.5539/par.v3n2p134 URL: http://dx.doi.org/10.5539/par.v3n2p134

\begin{abstract}
Because of the small target market and poor profitability of Orphan Drug, it is difficult to effectively encourage the R\&D and production Behavior of the Industry by the market mechanisms alone. So that, it is necessary to implement the incentive policy for Orphan Drug in order to stimulate the innovative behavior. Basing on the analysis of domestic market and foreign and innovative incentives policy, the paper discussed the policy factors of the innovative behavior for Chinese Orphan Drugs' industry by the research method of Structural Equation Modeling (SEM), and proposed the innovation incentive path, such as the registered priorities policy, industry-led incentive, new medical reform policy, and the policies collaborative mechanism.
\end{abstract}

Keywords: Orphan Drug, innovation, guiding policy, influence factor

\section{Introduction}

Realizing the social justice, caring for the life quality, improving the healthy level of the weaker group, maximizing the social welfare are the social managing issues which should be concentrated on all importantly by all governments of world. Rare diseases, as the typical representative of social weaker group, is difficult to be healed and Ebola hemorrhagic. So pay attention to and assuring the availability of its treatment and drugs is not only concert about the development of the national public care industry, but also closed cling to social homonym and stability. However, Rare Disease is a kind of diseases in the minority, its target market is small and its profitability is weaker. But it is very difficult to effectively encourage the company to R\&D yield the Orphan Drug only by the market mechanism. So it is necessary to explore the market guiding mechanism and government arming policy on the innovative behavior of Orphan Drug, to form good policy environment for the technical innovation in China and meet the constantly increasing requirement on health care for masses.

\section{Orphan Drug Market and Policy about New Healthcare Reform}

For Rare Disease, since as the disease in the minority, there neither is professional legislation on it. Nor it has been absorbed into 'low lever, broad coverage' healthcare insurance system. But some local government has done some significative institution searching on the guiding policy of Rare Disease or Orphan Drug.

\subsection{Orphan Drug Market}

After enter into 21 century, although the national healthcare level of masses has been improved continuously, because being regard as the disease in the minority, there is short of the practical treating way and drug for Rare Disease. The phenomenon of "suffering poor due to illness or the illness causing the poor" happened frequently in medical treatment and care field. On one hand, there is no professional legislation on Rare Disease; the distribution of the Rare Diseases and market supply level of the Orphan Drug is still uncertain. on the other hand, the encouraging mechanism to the innovative behavior on Orphan Drug is not formed; Till January of 2012, only few kinds of Rare Disease such as the Pompey can treated by practical drugs, sharing less than $1 \%$ of total number of Rare Disease; There is lower Listed level for Orphan Drugs from USA, Europe, Japan (table 1). According to figures, NSFC has cost 89,358,000.0 RMB during 1999-2007, to devote to the research of 32 kinds of Rare Disease, 10,000,000.0 RMB per year on average. But the USA has had an appropriation of 14,100,000.0 
USD only in 2010. In the security of Orphan Drugs, Chinese country is far fall behind Japan, south Korea, and Taiwan, also others BRICS, which is not adapt to Chinese national economy development level, especially the short input on R\&D must restrain the availability of Chinese Orphan Drugs and innovation initiative of the company.

Table 1. The public profile about some regions' Orphan Drugs

\begin{tabular}{cccc}
\hline Region & Total variety number & The public number in Chinese market & Proportion (\%) \\
\hline USA & 425 & 84 & 19.76 \\
Japan & 176 & 79 & 44.89 \\
European & 74 & 14 & 18.92 \\
Australia & 60 & 27 & 45 \\
Taiwan & 23 & 6 & 26.09 \\
\hline
\end{tabular}

Data resource: the data demonstration platform of Chinese national FDA

In case of the Deficiency of the institution associated with Rare Disease and Orphan Drug at the national level, some local governments have done some significative detect on the Rare Disease or demand market of Orphan Drug 1994, Shenzhen public healthcare bureau establish the "Chinese Rare Diseases magazine", and now is changed into "Rare Disease", which concentrates on theoretical study, diagnosing and treatment of Rare Disease. In recent years, Chinese CDC (Centers for Disease Control) has start to epidemiology analyses of some kinds of Rare Disease, and establishing national supervisory system of Creutzfeldt-Jakob disease in 2002. In June of 2010, Guangdong public healthcare bureau set up the indemnificatory fun for prevention and treatment of Rare Disease. In November of 2010, the first officially approved prevention and treatment association of Rare Disease, "Shandong prevention and treatment association of Rare Disease" was established formally. In 2011, the expertise branch of Rare Disease was built up by Shanghai medical association

\subsection{Orphan Drugs and Policy of New Healthcare Reform}

The healthcare insurance institution is a system that in a country or region, according to its insurance rule, raises, locates and makes use of the healthcare insurance fund to let masses can prevent or treat the disease. Currently, 4 patterns of insurance institution existed in China including free medical service, urban employees insurance, urban citizen insurance, and new rural cooperating medical insurance. In 2009, the launch of national new medical reforming plan, substantially improve the medical coverage rate of insurance coverage in China. But in this pattern of "low level, and broad coverage" medical insurance, no scheme concert on treatment and diagnose of Rare Disease was proposed.

Currently the patients of Rare Disease in Chinese mainly are confronting with difficulties from 3 aspects. Firstly, high misdiagnosis rate exist for Rare Disease, many patients cannot get correct diagnosis until transferring many hospitals. Secondly, there is no working drug available for most of the Rare Diseases, especially the inherited patients of Rare Disease. Thirdly, the Orphan Drugs are very expensive, even the middle class family can not afford for them, which plays the most important role in those three aspects. Now in China, the basic healthcare insurance is chiefly used pay the drugs and expenditure of treatment and diagnosis which are prescribed within drug category, treatment and diagnosing category, and healthcare facility standard. Usually the Orphan Drug can be concluded in the category of healthcare insurance, so the patients also have to bear the expensive treatment cost although they had taken part in the healthcare insurance.

\section{Policy and Innovation Incentive of Orphan Drug at Home and Board}

Not only the Special legislation of Rare Disease is most important unit of healthcare insurance system, there is also some motivation mechanism for the R\&D and product in many other countries or regions. But in Chinese, there is barely an institution design that Orphan Drug can enjoy preferred right on registration and approval. Still no incentive mechanism about related industrial guidance and healthcare insurance institution exists.

\subsection{National Policy about Orphan Drugs in Foreign Countries}

In 1980s, the Orphan Drug market is in state of free competition. But the low incidence of the Rare Disease results in the low benefit of Orphan Drug, and getting little attention from governments. Since from 1990s, many countries in the world have started to legislate on Rare Diseases to protect the right of patients and their families. 
At recently, In USA, Europe, Japan, their policy systems of Rare Disease and orphan are integrated, including R\&D, production, registration and approval, pricing, healthcare insurance, tax, social rescue and so on.

The "Orphan Drug Act" of USA was passed by congress in 1982, and was signed into law on April $1^{\text {st }}$ of 1983. In 2002, the "Rare Disease Act" and "Diseases Orphan Product Development" was passed which effectively motivate the development of Orphan Drugs and drive the long-term development of American bio-pharmacy. The EU parliament and council get No 141/2000 stature through, which get valid since from April $28^{\text {th }}$ of 2000. The EU has taken Rare Disease research as one of actions in public health field, and issued the "decision that absorbed rare dieses into public health plan in 2008-2013". Since on April $1^{\text {st }}$ of 2011, the European Medicines Agency had executed the exemption and deduction for the new Orphan Drugs expenditure. In November of 1993 the Japan formally issued and implanted “Orphan Drug Regulation”. Since September of 2003, the orphan drug center of South Korea have start to product and provide drugs and Orphan Drugs information, according to the amendment (law no.6982) of "South Korea act of pharmaceutical affair".

\subsection{Innovation Incentive Measure of Orphan Drug in Foreign Countries}

Most of countries provide the relevant incentives for the product and R\&D of the Rare Disease. The most frequent motivation is supplying the protection during the time of market exclusiveness, offering science advisory service for free, giving preferred registration and approval process, funding the R\&D of Orphan Drug. Still parts of countries deduct or exempt the tax and expenditure for the R\&D and product of Orphan Drugs.

All countries have prescribed time about market exclusiveness of the Orphan Drugs, which is the most working factor that drive the company enter into the orphan market, but the specific time is not different in each country. The market exclusiveness time In American is 7 years, in EU and Japans is 10 years. American and EU provide science advisory service for free, mainly integrating in clinical and non-clinical step of Orphan Drugs (table 2).because of high R\&D cost of Orphan Drugs, to promote the R\&D of Orphan Drugs, most of countries offer relevant grants or subsidies for research projects, such as "Orphan Drug office of American FDA" and "Japan's national bio-medical innovative mechanism", "EU DG Research".

The motivation method on tax concession for Orphan Drugs includes tax deducting or exempting in clinical cost, R\&D and other expenditure. For example in USA, the drugs can enjoy the tax concession if are approved as Orphan Drug. In France the sales promotion tax that the duty company must pay for promotion of Orphan Drug, is reduced. Severer countries have reduced some expense of Orphan Drug. The EU has reduced part of application fee for public license of Orphan Drug. The USA has reduced part of application fee and supplementary application fee for public license of Orphan Drug. 
Table 2. The feature of innovative act on Orphan Drug in some countries

\begin{tabular}{|c|c|c|c|}
\hline & countries & The policy feature of orphan drug & The new acts of orphan drug \\
\hline 1 & USA & $\begin{array}{l}\text { - Giving } 7 \text { years of market exclusiveness time } \\
\text { - Reducing the Tax of clinical test } \\
\text { - Awarding the subsidies from federal government } \\
\text { - Offering design assistance to clinical test } \\
\text { - Reducing registration expense } \\
\text { - Giving protocol assistance in R\&D step } \\
\text { - Offering preferential and faster speed review (6 } \\
\text { months) }\end{array}$ & $\begin{array}{l}\text { Orphan Drug Act (1983); Orphan Drug } \\
\text { Regulations: Final Rule June 12, } 2013\end{array}$ \\
\hline 2 & Japan & $\begin{array}{l}\text { - } 10 \text { years of market exclusiveness time } \\
\text { - Offering Fast approval gas; } \\
\text {-Offering free advisory service } \\
\text { - Giving financial support and research fund }\end{array}$ & Orphan Drug Regulation (1993) \\
\hline 3 & EU & $\begin{array}{l}\text { - Offering } 10 \text { years of market exclusiveness time } \\
\text { - Decreasing the expense of integrated review } \\
\text { - Offering advisory service and protocol assistance } \\
\text { for free } \\
\text { - Offering the marketing authorization of EU } \\
\text { communities. } \\
\text { - Reducing } 100 \% \text { of its expenditure after getting } \\
\text { marketing authorization for small and medium } \\
\text { enterprises. }\end{array}$ & Regulation (CE) No 141/2000 \\
\hline 4 & Australia & $\begin{array}{l}\text { - healthcare insurance Covers all expense in } \\
\text { prescribed process } \\
\text { - Remitting the assessment and application fee } \\
\text { - Having no registration annuity. } \\
\text { - Giving } 5 \text { years of market exclusiveness time }\end{array}$ & Orphan Drug Policy (1998) \\
\hline 5 & Taiwan & $\begin{array}{l}\text {-Offering } 10 \text { years of market exclusiveness time } \\
\text { - Cutting off clinical test if authorized by FDA. }\end{array}$ & $\begin{array}{l}\text { Rare Disease and Orphan Drug Act } \\
(2000)\end{array}$ \\
\hline 6 & Singapore & $\begin{array}{l}\text { - Ministry of health offers the most registration } \\
\text { priority. }\end{array}$ & Drug Exemption Order (1991) \\
\hline
\end{tabular}

\subsection{Relevant Incentive Method of Orphan Drugs in Chinese}

At present, many countries have issued government guiding policy for the Rare Disease and Orphan Drug, but Chinese seems be slower in formulating incentive method of Orphan Drugs, which mainly focuses on registration and review links. 2007, issued "Chinese drug administration act" was issued, and the article 45 stipulates that the new drugs which can work with HIV, cancer, Rare Disease and have clear clinical treatment superiority could get the particular approval for its application.

The "Act of special examination and approval in new drug "issued in 2009 stipulates that take Orphan Drug into arrange of special examination and approval.

The "Act on intensifying the reform of examination and approval to encourage more innovation "issued in 2013 proposes that encourage drug innovation that oriented toward clinical value. "The $12^{\text {th }}$ five-year plan of national drug security" point out encourage R\&D of Orphan Drug and children-appropriate dosage. Many policy and law offer system assurance in allowing innovative product of orphan go public fast. 
But Chinese country still do not issued special incentive act associated with the R\&D, product and usage of Orphan Drugs. In the hand of privileges for high technology enterprise, if drugs are authorized as Orphan Drugs by the approval section, their enterprises can get state major support and enjoy sever kinds of tax priority as high technology enterprises. In the use of Orphan Drugs, Rare Disease, and Orphan Drugs still have not been specially arranged in national or local healthcare insurance system. The expensive cost and small target market causes the failure in showing incentive effect of innovative behavior for Orphan Drugs companies. So aim at institutional deficiency on R\&D, registration, production and operation of Orphan Drugs, it is necessary to provide particular innovative method.

\section{Analysis of Policy Impact Factors on Innovative Behavior for Chinese Orphan Drugs}

Based on the scheme that motivation policy system of innovative behavior for Chinese Orphan Drugs has not be established, we implement the analysis of Policy impact factors on Innovative Behavior for Orphan Drugs ,to explore synergistic effect among the guiding policies of government and motivate innovative Behavior for Chinese Orphan Drugs companies, improve the availability of Orphan Drugs.

\subsection{Proportion of Hypothesis and Collection of Questionnaires}

Innovative behavior for Orphan drugs is epitome of all national policies. The industry boosts the integration among policy, registration and approval system, new medical reform policy. As a result of researching foreign documentations on technical innovative policies for Orphan Drugs, we supposed in this paper that there is synergistic effect between technology innovation of Orphan Drugs and guiding policies. (Figure 1), and propose the hypothesis model, analyze the questionnaires to verify hypothesis.

There is synergistic effect among drug registration and approval institution technical guiding policies, and new medical reform method.

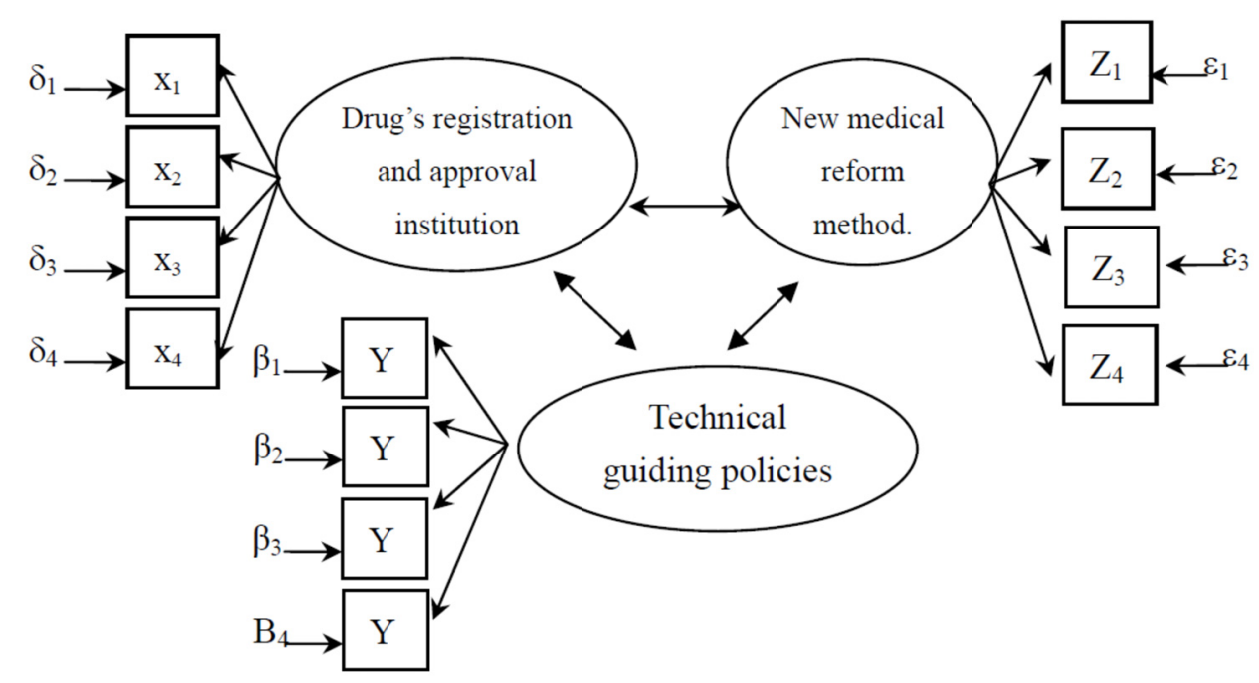

Figure 1. The hypothesis model analyzing the policy impact factors on innovative behavior for Chinese Orphan Drugs

The group for $R \& D$, registration, production and operation of Orphan Drugs is special; the questionnaires chiefly are distributed to the employees in medical healthcare field. 500 questionnaires are issued, 260 pieces are taken back, and 248 pieces are valid. The industry, working year, contacting frequency and such 6 questions are included in questionnaires. The figures are deal with software of SPSS13.0 and LISREL8.80. The basic information is as follows (table 3 ) 
Table 3. The questionnaires basic information about impact factors on innovation incentive policy of Chinese Orphan Drugs

\begin{tabular}{|c|c|c|c|c|c|c|c|}
\hline & & frequency & Percent & & & frequency & Percent \\
\hline \multirow{7}{*}{ industry } & Education & 35 & $14.1 \%$ & \multirow{7}{*}{ administrative level } & & & \\
\hline & supervisory & 2 & $0.80 \%$ & & senior management & 20 & $8.1 \%$ \\
\hline & $\mathrm{R} \& \mathrm{D}$ & 103 & $41.5 \%$ & & middle class & & \\
\hline & healthcare & 12 & $4.80 \%$ & & management & 52 & $21.0 \%$ \\
\hline & Production and & & & & front line management & 42 & $16.9 \%$ \\
\hline & operation & 45 & $18.1 \%$ & & common employees & 134 & $54.0 \%$ \\
\hline & Relevant R\&D & 51 & $20.6 \%$ & & & & \\
\hline \multirow{4}{*}{ working years } & $1-3$ years & 67 & $27.0 \%$ & \multirow{4}{*}{ contacting chance } & no & 119 & $48.0 \%$ \\
\hline & 4-10 years & 82 & $33.1 \%$ & & occasional & 114 & $46.0 \%$ \\
\hline & $11-20$ years & 68 & $27.4 \%$ & & usual & 12 & $4.8 \%$ \\
\hline & More than 20 years & 31 & $12.5 \%$ & & other situation & 3 & $1.2 \%$ \\
\hline
\end{tabular}

Figure resource: In 2013, 6-8, the research result of nationwide questionnaires about innovation behavior Policy of Chinese Orphan Drugs

\subsection{Statistic and Analysis of the Figures}

Based on survey figure about impact Factors on innovation incentive Policy of Chinese Orphan Drugs, we make description statistic and verifying factor analysis to get synergistic effect of technical innovation policies of Orphan Drugs for the reference of relevant department about Orphan Drugs

The result of impact factor analysis on innovation incentive policy for Orphan Drug with description statistic (table 4) show that the mean value of impact factor concerning on drugs' registration and approval institution is lower, the standard deviation and coefficient of variation is higher, reflecting that insiders have dispersed opinion on innovation behavior of Orphan Drugs' registration and approval institution. Comparatively, there is higher mean value for impact factor concerning on industry guiding policy. its standard deviation and coefficient of variation is lower, reflecting that insiders have agreed positive effect of industry guiding policies. For the impact factors concerning on basic drugs administrations, the healthcare insurance institution, and reimbursement ratio in new medical reform, the mean value is lower, its standard deviation and coefficient of variation is higher, which means insider should improve their cognition of relevant incentive measure about new medical reform. 
Table 4. The questionnaire and description statistics of impact Factors about innovative behavior Policy of Chinese Orphan Drugs

\begin{tabular}{|c|c|c|c|c|c|}
\hline \multirow{2}{*}{$\begin{array}{l}\text { The incentive policies about } \\
\text { innovative behavior }\end{array}$} & \multirow[b]{2}{*}{ code } & \multirow[b]{2}{*}{ item } & \multicolumn{3}{|c|}{ description statistic } \\
\hline & & & $\begin{array}{l}\text { mean } \\
\text { value }\end{array}$ & $\sigma$ & $\mathrm{CV}$ \\
\hline \multirow{5}{*}{$\begin{array}{l}\text { (drugs' registration and } \\
\text { approval institution) }\end{array}$} & $\mathrm{X} 1$ & Preferential approval and green gas & 5.20 & 1.59 & 0.31 \\
\hline & $\mathrm{X} 2$ & Positive communication system of developer & 5.14 & 1.52 & 0.30 \\
\hline & $\mathrm{X} 3$ & The product license is belong to developer & 4.80 & 1.46 & 0.31 \\
\hline & $\mathrm{X} 4$ & Shorten the Clinical test period & 4.86 & 1.57 & 0.32 \\
\hline & $\mathrm{X} 5$ & Guide the program design of clinical test. & 5.04 & 1.46 & 0.29 \\
\hline \multirow{6}{*}{ (industry guiding policies) } & Y1 & establish transfer mechanism of R\&D fruit & 5.68 & 1.27 & 0.22 \\
\hline & $\mathrm{Y} 2$ & special polices technology and production & 5.39 & 1.36 & 0.25 \\
\hline & Y3 & protecting policies about intelligence property & 5.54 & 1.33 & 0.24 \\
\hline & Y4 & $\begin{array}{l}\text { the fixed-supplier purchasing policies of } \\
\text { government }\end{array}$ & 5.35 & 1.38 & 0.26 \\
\hline & Y5 & the preferential tax policies & 5.42 & 1.44 & 0.27 \\
\hline & Y6 & government grant policy by funding capital & 5.81 & 1.20 & 0.21 \\
\hline \multirow{4}{*}{ (new Medical reform method) } & $\mathrm{Z1}$ & Enter into the national essential drug list & 4.74 & 1.79 & 0.38 \\
\hline & $\mathrm{Z} 2$ & Enter into the NRDL & 4.81 & 1.78 & 0.37 \\
\hline & $\mathrm{Z3}$ & Enter into the PRDL & 4.67 & 1.72 & 0.37 \\
\hline & $\mathrm{Z} 4$ & $\begin{array}{l}\text { The reimbursement ratio in the nation healthcare } \\
\text { insurance system }\end{array}$ & 5.21 & 1.53 & 0.29 \\
\hline
\end{tabular}

Figures resource: In 2013, 6-8, the research result of nationwide questionnaires about innovation behavior Policy of Chinese Orphan Drugs

Confirmatory factor analysis in the SEM associated with influencing factor of innovation incentive policies for Orphan Drug shows that" $\chi^{2} / \mathrm{df}=2.67$ ", all the mean value of CFI, NNFI, GFI, IFI is higher than 0.90 , $\mathrm{SRMR}=0.069$, RMSEA $=0.081$, the analysis result is as follow (table 5)

In register and approval institution (Register), the communication mechanism between government and enterprise, the marketing authorization holder system (production license belong to developer), the program steering are the main factors which influencing the register and approval of Orphan Drugs; the facilitated policies of technology and production, government's fixed supplier purchasing, and capital investment of government, are the chief hands of guiding policies of industrialization for Orphan Drugs. Entering into remenbursement list of national or local healthcare insurance plays an essential role motivates the usage of Orphan Drugs.

There is higher path coefficient between "register and approval institution" (Register) and "industrial guiding policies" (Policy), but path coefficients between "new medical reform method" (Medical) and both factors above are lower (table 6), which shows that register and approval institution has strong relationship with industrial guiding policies, has no relevancy with new medical reform method. 
Table 5. Confirmatory factor analysis table associated with influencing factor of innovation incentive policies for Orphan Drug

\begin{tabular}{ccccl}
\hline $\begin{array}{c}\text { The incentive policies of } \\
\text { innovative behavior }\end{array}$ & code & $\begin{array}{c}\text { verifying } \\
\text { The value of } \mathrm{T}\end{array}$ & $\begin{array}{c}\text { Standard } \\
\text { system }\end{array}$ & \multicolumn{1}{c}{ reliability analysis } \\
\hline X1 & 7.65 & 0.50 & $\alpha$ coefficient $=0.771$ \\
(Register) & X2 & 12.19 & 0.73 & KMO value $=0.800$ \\
register and approval & X3 & 10.95 & 0.68 & Bartlett's verification: \\
institution & X4 & 8.95 & 0.57 & (approximate CMIN) $=306.25$ \\
& X5 & 11.71 & 0.71 & df $=10 \quad$ sig $=0.000$ \\
& Y1 & 10.64 & 0.65 & $\alpha$ coefficient $=0.839$ \\
(Policy) & Y2 & 12.54 & 0.73 & KMO value $=0.844$ \\
industrial guiding & Y3 & 11.47 & 0.68 & Bartlett's verification: \\
policies & Y4 & 11.94 & 0.71 & approximate CMIN $=306.25$ \\
& Y5 & 10.84 & 0.66 & df $=15$ sig $=0.000$ \\
& Y6 & 11.41 & 0.68 & \\
(Medica) & Z1 & 13.99 & 0.76 & $\alpha$ coeffients $=0.911$ \\
medical reform & Z2 & 21.02 & 0.98 & KMO value $=0.801$ \\
method & Z3 & 19.06 & 0.93 & Bartlett's verification: \\
& Z4 & 13.52 & 0.74 & approximate CMIN $=822.79$ \\
& & & & df $=6$ sig $=0.000$ \\
\hline
\end{tabular}

Figures resource: In 2013, 6-8, the research result of nationwide questionnaires about innovation behavior Policy of Chinese Orphan Drugs

Table 6. The path coefficients of innovation incentive policies for Orphan Drug

\begin{tabular}{cccc}
\hline & Register & Policy & Medical \\
\hline Register & 1.00 & & \\
Policy & 0.70 & 1.00 & \\
Medical & 0.07 & 0.16 & 1.00 \\
\hline
\end{tabular}

\subsection{Result and Discussion}

The result of empirical analysis on incentive policies factors influencing Orphan Drugs innovation show that totally, insiders pay much attention to guiding policies, there is obvious relationship between industrial guiding policies and register and approval system, and the new medical reform measure just has little relevancy with industrial guiding policies and register and approval system.

The register and approval system of Orphan Drug plays a very important part before marketing, positive communication between developer and supervisory section, the marketing authorization holder, design steering of clinical program and such factors influence the marketing and usage of Orphan Drugs. At present, Chinese government has issued some facilitated policies about Orphan Drugs' register and approval system, stimulated the R\&D orientation toward purpose of clinical use. But the feature of high R\&D cost and small market demand still can not motivate technology innovation of Orphan Drugs companies. In the hand of government's industrial promotion, sun as the technology and production facilitated policies, the fixed suppler purchasing of government, and preferential tax strategy all are closed associated with the innovative behavior of Orphan Drugs companies. But in Chinese, no guiding polices about Rare Disease or Orphan Drugs are issued till now. Under the back ground of national new medical reform and industrial structure adjustment, positively carrying out the innovation incentive mode of Orphan Drugs will efficiently motivate the technology innovation behavior of bolo-medical industry.

The guiding policies of Orphan Drug concerting on new medical reform has no correlation with register and 
approval system, has weak correlation with industrial guiding policies, which indicate that among all varieties of guiding policy related to innovative motivation of Orphan Drugs ,the synergy is shorted. So driving demand market of Orphan Drugs by taking advantage of healthcare insurance system and establishing motivation mechanism of innovative behavior, are efficient ways about innovation incentive policies of orphans drugs.

\section{Incentive Path of Innovative Behavior for Chinese Orphan Drug}

In China, the innovation incentive polices of Orphan Drug firstly is showed on register and approval step, but in hands of investment and assistance to $\mathrm{R} \& \mathrm{D}$, production and operation, healthcare insurance, no special incentive policies are existed. So the synergy effective among all government policies is essentially to motivate innovative behavior about Orphan Drugs.

\subsection{Priority Polices in Drugs' Register and Approval Step}

Recently, in Chinese, the translation from founded research achievement into clinical use of Orphan Drug has obviously lagged, which may result from disperse of patients, few patients resource, high R\&D cost and so on. So it is very difficult to implement a clinical test and detailed pathological mechanism research. However, Chinese should taking advantage of the relative abundant Rare Disease resource, establish Rare Disease library quickly, build national even globe Rare Disease network to service for Orphan Drugs' research. The global popular method "identify authentication and marketing license" should be Referenced in registering the Orphan Drugs to confirm their identify authentication.

In accordance with "Act of new drugs' special approval", establishing communication system between register and approval section and developer, getting the preferred marketing license authority, properly decreasing the clinical patients and short approval period, supplying aid to the design of clinical program and such methods, setting up administrative protecting time and special individual approval gas for Orphan Drugs, which stipulates approval time limitation of the special gas and reducing standard of relevant expense, will lower the resister and marketing cost of Orphan Drugs epically imported varieties. At the same time, implementing cooperation of "major new drugs discovery initiatives in Chinese ministry of science and technology" and "the committee of Chinese Natural Science Fund" can supply the capital fund in earlier time of Orphan Drugs' R\&D project.

\subsection{Incentive Polices Associated with $R \& D$ and Production Step}

Because the small target Market and monopoly position of Orphan Drugs, it is necessary to adopt incentive polices related with innovation R\&D of Orphan Drugs, the priority strategies of production tax, market guarantee and such administrative method for government to assure the availability of Orphan Drug. By creating and improving intrinsic incentives of the Orphan Drugs companies and also the external environment of market supply, companies' resource can be configured more appropriately and can be made use of more effectively, which guarantee the maximize of social public healthcare welfare in Chinese.

For governments, implementing the fixed-supplier purchasing, capital investment, tax priority and such guiding policies is necessary, which can boost R\&D and production enthusiasm of Orphan Drugs companies. Especially, in $R \& D$ step, driving the preferred register and approval policies engage with translation mechanism of R\&D fruit and system of intelligence poverty protection, and issuing the special facilitated polices for Orphan Drugs' technology and production will get the R\&D and production force of Orphan Drugs improved.

As the using time went on and clinical experience was summarized about Orphan Drugs, expanding its arrange of clinical indications, registering and approving new clinical indications will become bombshell in international market in promoting the profitability of companies, such as GLEEVEC developed by NOVARTIS AVASTIN developed by Roche and Genentech. So advocating further research about pharmacy mechanism of Orphan Drugs may become theory foundation of innovative research in bio-medical industry and boost increasing growth of globe medical innovative level.

\subsection{Guiding Polices Associated with Healthcare System Reform}

The Orphan Drug is very expensive, the treatment expense of partial Rare Disease far exceeds than individual affordability. So offering assurance to patients of Rare Disease with healthcare insurance can increase the availability of Orphan Drugs in one hand, stimulate innovative force of their companies on another hand. Always relying on the imported drug is not long tern solution to problems of Chinese Orphan Drugs market. For those Orphan Drugs aimed to high incidence Rare Disease in Chinese, but has been marketed in aboard, the government should establish price negotiation mechanism, or fixed supplier purchasing way, carry out healthcare insurance coverage to enlarge its target markets and stimulate the innovative enthusiasm of companies. Such as organize all departments and consulting expert team to have comprehensive consideration about clinical efficacy, patients' number, foreign guarantee and confirm the price, absorb into national healthcare insurance system. By 
researching the figures and practical experience in income level, healthcare expenditure, and disposable healthcare resource of all countries, Chinese can maintain the best time to absorb Orphan Drug into planed immunity scope, which reflects the fairness and popularity of Chinese healthcare insurance system.

\subsection{Synergism Effect of All Incentive Polices from Government}

The exploration and innovation about Orphan Drugs' policies, can resolve market demand of Orphan Drugs, but also can strengthen the translation of medical development, and accelerate innovative research and structure adjustment of bio medicine industry. But the result of the empirical analysis reflects that in Chinese there is short of synergy among all incentives polices about Orphan Drugs. Thus, engaging the healthcare insurance policy with register and approve, particular technology innovation and industrial guiding policies so on effectively to construct an integrated policy system related to incentive mechanism of Orphan Drugs' innovative behavior, further motivate its innovative behavior and availability, market demand .

Under the background of current new medicine reform policy and developing plan of industrial structure adjustment, all innovation incentive polices should work systematically to resolve motive shortage problem for bio- medical industry in structural adjustment, optimization and upgrade during the $12^{\text {th }}$ five-years plan. Referenced regulating experience of Orphan Drug from American FDA, establishing special management section about Orphan Drugs, who harmonize the relationships among all section, play a coordinating roles in register and approve, price regulating, industrial guiding policies, healthcare insurance can effectively motivate the innovative behavior of Orphan Drug companies.

\section{References}

Gericke, C. A., Riesberg, A., \& Busse, R. (2005). Ethical Issues in Funding Orphan Drug Research and Development. J Med Ethics, 31(3), 164-168. http://dx.doi.org/10.1136/jme.2003.007138

Gong, S. W., \& zhang, L. (2011). Analysis on different care service demand between common disease and rare disease hospital patients in Chinese. Chinese Health Economy, 30(2), 39-41.

$\mathrm{Gu}$, J. L. et al. (2013). Contrastive analysis about developing statue of orphan drug polices in china and abroad. Soft Science of Health, 27(7), 393-396.

Han, J. X., Cui, Y. Z., \& Zhou, X. Y. (2011). The research status and prospect of rare disease. Rare Disease Magazine, 18(1), 1-6.

Lin, Y. H., \& Wu, X. M. (2011). The EU solution to rare disease and its illumination for Chinese. Zhejiang Social Science, (10), 149-154.

Liu, Y. C., \& Dong, W. P. (2012). The research about management status of EU orphan drugs. Journal of Chinese Medicine, (5), 395-398.

Shi, Q. et al. (2008). Surveillance for Creutzfeldt-Jakob disease in China from 2006 to 2007. BMC Public Health, (8), 360. http://dx.doi.org/10.1186/1471-2458-8-360

Tao, Y., Shao, Y. F., \& Zhang, C. (2002). The management system of Orphan Drug in Japan. Journal of Chinese Medicine, (6), 69-71.

Zeng, Z., Yang, Y., \& Ling, H. C. (2009). Proposed discussion and suggestion about Chinese orphan drugs' policies. China Pharmacy, (10), 737-740.

Zhou, M. Q. (2004). The legislation background of American "Orphan Drugs Act”. Capital Medicine, (15), 50-51.

\section{Copyrights}

Copyright for this article is retained by the author(s), with first publication rights granted to the journal.

This is an open-access article distributed under the terms and conditions of the Creative Commons Attribution license (http://creativecommons.org/licenses/by/3.0/). 